\title{
A meta-synthesis on parenting a child with autism
}

This article was published in the following Dove Press journal:

Neuropsychiatric Disease and Treatment

5 April 2016

Number of times this article has been viewed

\author{
Khim Lynn Ooi \\ Yin Sin Ong \\ Sabrina Anne Jacob \\ Tahir Mehmood Khan \\ School of Pharmacy, Monash \\ University Malaysia, Bandar Sunway, \\ Selangor, Malaysia
}

Background: The lifelong nature of autism in a child has deep implications on parents as they are faced with a range of challenges and emotional consequences in raising the child. The aim of this meta-synthesis was to explore the perspectives of parents in raising a child with autism in the childhood period to gain an insight of the adaptations and beliefs of parents toward autism, their family and social experiences, as well as their perceptions toward health and educational services.

Methods: A systematic search of six databases (PubMed, EMBASE, PsychInfo, Cochrane Central Register of Controlled Trials, Cochrane Database of Systematic Reviews, and Database of Abstracts of Reviews of Effects [DARE]) was conducted from inception up to September 30, 2014. Full-text English articles of qualitative studies describing parents' perceptions relating to the care of children younger than 12 years of age and diagnosed with a sole disorder of autism were included.

Results: A total of 50 eligible articles were appraised and analyzed, identifying four core themes encompassing all thoughts, emotions, and experiences commonly expressed by parents: 1) The Parent, 2) Impact on the Family, 3) Social Impact, and 4) Health and Educational Services. Findings revealed that parents who have a child with autism experienced multiple challenges in different aspects of care, impacting on parents' stress and adaptation.

Conclusion: Health care provision should be family centered, addressing and supporting the needs of the whole family and not just the affected child, to ensure the family's well-being and quality of life in the face of a diagnosis of autism.

Keywords: autistic spectrum disorder, childhood, adaptation, meta-synthesis

\section{Introduction}

Autistic spectrum disorder (ASD), generally known as autism to the public, is a developmental disorder that varies in manifestation between affected individuals in terms of onset, severity, and symptoms. ${ }^{1-3}$ The prevalence of autism has been on the rise from one in 150 children in the year 2000 to one in 68 children in the year 2010 in the USA. ${ }^{4}$ The observed increase in prevalence is in part due to an increase in awareness and health service provision, as well as improvements in diagnostic practices, leading to earlier detection and diagnosis of children with autism. ${ }^{5,6}$ Symptoms of autism typically appear during the early years of childhood, when parents realize that their child has not achieved the expected milestones of child development. Instead, development is described as delayed or absent. ${ }^{2,7-9}$ Parents realize either that their child does not respond to parental cues of affection or communication or that the child does not show affection or speak. ${ }^{2,9}$ The child's behavior may also become abnormal or disruptive. ${ }^{1,2,9}$ These symptoms spark concern, prompting parents to seek professional help, leading to a diagnosis of ASD. ${ }^{2}$

Core symptoms include deficits in social interaction and communication, described as the inability to initiate and respond to both verbal and nonverbal social cues. ${ }^{7,9}$
Correspondence: Tahir Mehmood Khan School of Pharmacy, Monash University Malaysia, Jalan Lagoon Selatan, 47500 Bandar Sunway, Selangor, Malaysia

Tel +60355144418

Fax +60355I46364

Email tahir.mehmood@monash.edu 
Thus, children with autism commonly isolate themselves and have difficulty in maintaining reciprocal interactions. ${ }^{9}$ They may lack shared interests with other children and do not play with toys enjoyed by typical children of the same developmental age. ${ }^{9}$ Children with autism may also lack emotional expressions or have inappropriate affect to the social context in question. ${ }^{9}$

Distress can occur due to sensory hypersensitivities such as to touch and sound, and their highly routinized and stereotypical behaviors characteristic of autism further contribute to this distress, whereby a diversion from normal routine can result in tantrums. ${ }^{10,11}$ Other core symptoms involve the lack of or poor language skills and repetitive speech. ${ }^{9}$ ASD has no cure and is lifelong; ${ }^{12}$ thus, currently available treatments are not directed for cure but are aimed at improving the overall functioning of the child with autism. ${ }^{13}$

\section{Parents as caregivers}

The lifelong nature of autism has deep implications on parents of children with the disorder, resulting in a wide range of challenges. This is because parents, especially mothers, are generally the primary caregiver of children with autism. ${ }^{14}$ First, caring for a child with autism is not without emotional consequences. ${ }^{11,14-17}$ Upon receiving the diagnosis, parents are faced with the loss of expectations for a typically developing child and are faced with uncertainties regarding not only the child's but also the family's future. ${ }^{1,15,18}$ Additionally, the child's problematic behavior, attributable to their intolerability to changes in the environment and highly routinized behavior, makes parenting demanding and difficult. ${ }^{11}$ This happens especially when parents are inexperienced, for example, parents with a first child diagnosed with autism or who are new to the disorder. ${ }^{17,19}$ Impairments in the parent-child relationship may occur as a result, leading to poor parenting, increased stress levels, and vice versa. ${ }^{20,21}$ Findings in the literature have shown that mothers caring for a child with autism have higher perceived stress levels. ${ }^{15,17,22-24}$ Fathers are also not exempted from increased stress levels, though different aspects of the child's behaviors and external stressors are found to contribute to fathers' stress levels compared to mothers' ${ }^{17,25}$ However, there remains a sizeable gap in the literature with regard to the factors that contribute to parents' stress levels while caring for a child with autism, highlighting the need for further exploration in order to determine how to better support families dealing with this disorder.
Rationale for conducting a meta-synthesis The aim of this meta-synthesis is to systematically pool together qualitative studies on the perceptions and experiences of parents of children with autism, with the purpose of providing an insight on what such parents face. A qualitative meta-synthesis is a process that involves the amalgamation of a number of similar qualitative studies with the primary purpose of developing a deeper explanation of their findings, within a particular context, as opposed to a meta-analysis that seeks to define cause-and-effect inferences. ${ }^{26}$ Schreiber et $\mathrm{al}^{27}$ described meta-synthesis:

As a literature assessment method to assist the researchers to pool the results from the published literature and analyze the issues under discussion by breaking the findings in themes, examining them, discovering essential features and, in some way, combining phenomena into a transformed whole.

Thus, giving a concise opinion about the issue under discussion and identifying the gaps that can be addressed as a potential hypothesis or as a study question in future.

In the literature, two meta-syntheses relating to parents' experience with a child with autism have been found. ${ }^{28,29}$ DePape and Lindsay ${ }^{28}$ used the Family Life-Cycle Model to describe the challenges of having a child with autism at several stages of the family life, from prediagnosis up to adolescence. Therefore, this meta-synthesis provided a chronological view on the challenges faced, how parents adapted to the disorder, and how the challenges changed with time. The meta-synthesis by Corcoran et $\mathrm{al}^{29}$ focused instead on various aspects of parents' experience in the USA, generalizing its findings to the policies and services available to the autism population in the USA.

The current meta-synthesis will also describe the challenges of caring for a child with autism in a worldwide context, but only in the childhood period. This is to provide an in-depth focus on parental experiences while caring for young children with autism, as experiences have been shown to differ between parents caring for a young child with autism compared to an adolescent or an adult with autism. ${ }^{30}$ Furthermore, this meta-synthesis will explore the adaptive behaviors and beliefs of parents toward autism, their family, and social experiences, as well as parents' perceptions toward health and educational services. The positive aspects of caring for a child with autism will also be explored.

\section{Methods}

\section{Search strategy and screening process}

Six databases were searched from inception up to September 30,2014 , for articles relating to parents' perceptions of their 
children with autism. Databases searched included PubMed, EMBASE, PsychInfo, Cochrane Central Register of Controlled Trials, Cochrane Database of Systematic Reviews, and Database of Abstracts of Reviews of Effects (DARE). Search terms used for the retrieval of articles combined the following sets of keywords:

1. Adaptation, affect, emotion, attitude, parenting, relationship, and qualitative;

2. Autism, ASD, autistic disorder, Asperger, and pervasive; and

3. Parents, father, and mother.

Boolean "AND" was used to connect search terms between the three sets of keywords while "OR" was used to connect search terms within each set of keywords. Truncations "**" were also used to pluralize search terms where possible to further refine the search. Articles were limited to search terms in titles and abstracts, journal articles with an English abstract, and human studies. After removal of duplicated articles, titles and abstracts were screened independently by the first two authors. Full-text articles were then read for inclusion eligibility. Any discrepancies were resolved through discussion and mutual agreement. If an agreement could not be met, the supervising authors were then consulted for advice.

\section{Criteria for inclusion}

Articles for inclusion included those that described the attitudes, concerns, or experiences of parents while caring for a child with autism as characterized by Diagnostic and Statistical Manual of Mental Disorders, Fifth Edition: autistic disorder, Asperger's syndrome, and pervasive developmental disorder not otherwise specified. Autistic disorders not classified under Diagnostic and Statistical Manual of Mental Disorders, Fifth Edition were not included such as infantile autism, Fragile X syndrome, and Rett's syndrome. However, studies that used the International Classification of Diseases, Tenth Revision or even parental reports for confirmation of a diagnosis of autism were accepted for inclusion. The child's characteristics that determined inclusion into the meta-synthesis were limited from the time the child received a diagnosis up to the age of 12 years, thus focusing only on children in their childhood period. However, a few exceptions were made where the author considered that the age of the child included in the study could be selectively excluded or would not have had a significant impact on the overall results.

\section{Criteria for exclusion}

Articles excluded were those that did not have an English translation, did not report the methodology for the study; described disorders, symptoms, or interventions not related to the autistic spectrum such as Attention Deficit Hyperactivity Disorder or the use of measles, mumps, and rubella vaccine or anesthetics; described the care of children with autism with comorbidities such as deafness and anxiety disorder; and described the perception of parents in relation to siblings of children with autism. Articles that were comparative studies of autism with intellectual or mental health disorders, case studies, thesis, reports, or purely quantitative studies were also excluded.

\section{Analytical methodology}

The first 25 articles identified were read in full, focusing on identifying the different implications a child with autism had on parents, in order to develop initial core themes. These articles were then reread, highlighting and categorizing important quotes, statements, and sentences that provided an understanding of parents' experiences, into core themes and compiled into a database. Key aspects of each study were also summarized for comparison of findings across studies. Data compiled were analyzed via a phenomenological approach for recurring patterns related to the perspective of parents in their adaptation, needs, and experience, while caring for a child with autism, and codes were developed for each pattern. Based on this analysis, domains within each core theme were then developed to capture notable perspectives. The remaining included articles were then read, and relevant data compiled into these themes and domains.

\section{Protocol and registration}

The protocol for this study has been registered with PROSPERO (registration number: CRD42015015756) and can be accessed at. ${ }^{31}$

\section{Results Search results}

The search yielded a total of 3,146 articles. After exclusion of duplicates and screening of titles and abstracts, 246 potentially eligible articles were identified. Of these, 196 articles were excluded. Major reasons for exclusion were 1) quantitative methodology of the study, 2) combination of child participants with adolescent or adult participants, 3 ) presence of comorbidities in child participants, and 4) articles that were case studies, case reports, or theses. A final number of 50 articles were included in this meta-synthesis (Figure 1).

\section{Characteristics of included articles}

Overall, the included articles were observed to have either a general focus $(n=29)$ on parents' perspectives or a specific 


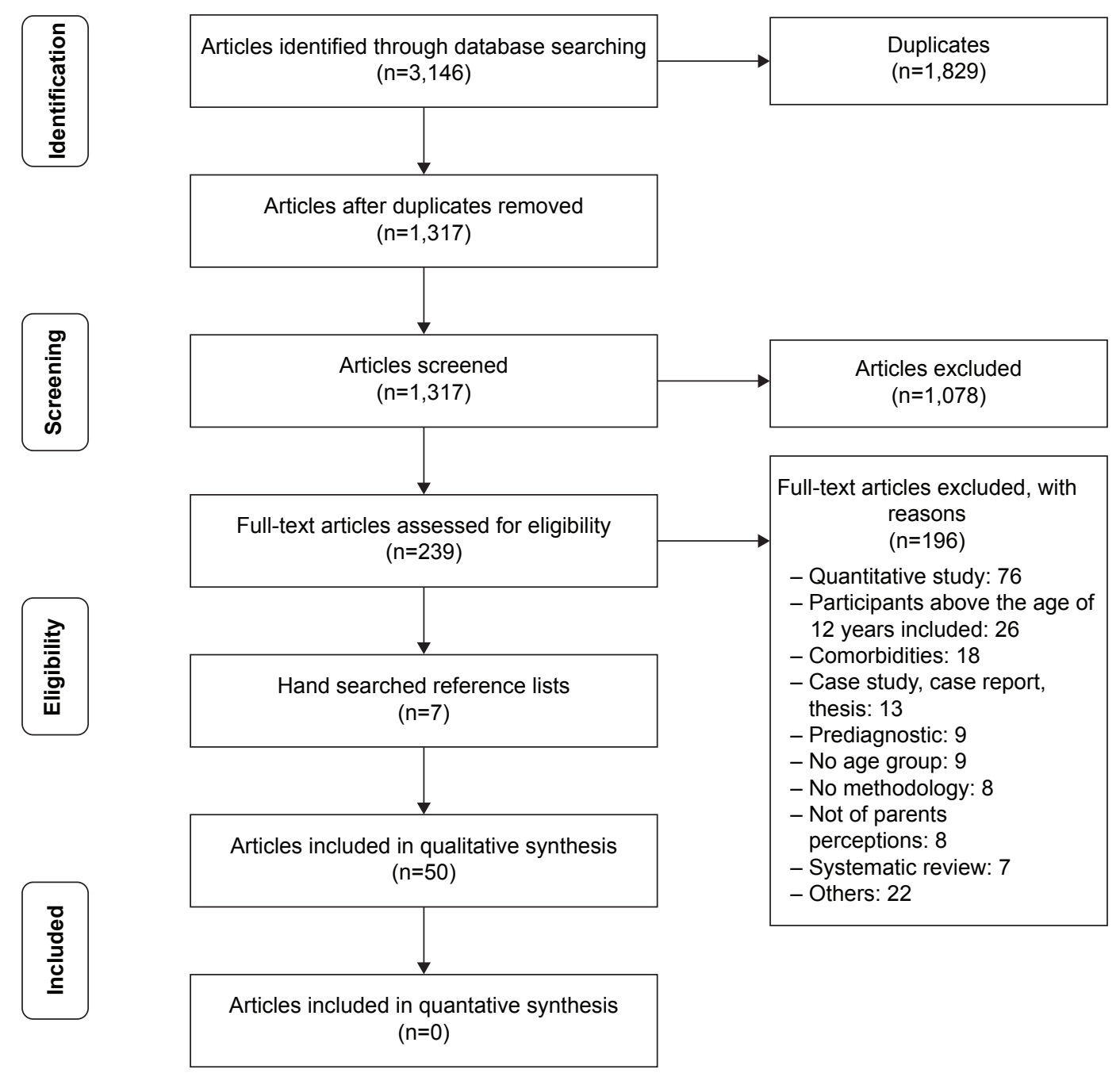

Figure I PRISMA flowchart for search process.

Abbreviation: PRISMA, Preferred Reporting Items for Systematic Reviews and Meta-Analyses.

focus ( $n=21)$. Articles with a general focus described various aspects of personal, familial, and social life in relation to the child with autism, their ability to cope with the diagnosis, and strategies in dealing with the child's problematic behaviors. Articles having a specific focus instead, mainly described health services as well as social support and stigma toward autism.

\section{Study characteristics}

Most studies were conducted in the USA ( $n=17)$, followed by the UK $(n=6)$, Europe $(n=5)$, Australia $(n=5)$, Canada $(n=5)$, and the People's Republic of China $(n=4)$. Two studies were conducted in Turkey, while one study each was conducted in India, Mexico, Taiwan, South Africa, Saudi Arabia, and Malaysia. All studies focused on autism in general, whereby none focused on a specific type of diagnosis of autism.
Sixteen articles focused on the perspective of mothers only, one on fathers only, while 33 articles focused on both. Of the 33 articles, four had an equal number of mothers and fathers. The majority of included articles utilized semistructured interviews ( $\mathrm{n}=38)$, six studies conducted focus group interviews, one had a combination of both, and five studies used openended questionnaires to obtain qualitative data.

\section{Participant characteristics}

A total of 1,675 parents' responses were included, involving 1,616 child participants (Table 1). Among the articles that reported the sex of the child, the ratio of boy to girl participants was $\sim 1: 5$. The exact number of children having each specific diagnosis on the autism spectrum could not be determined due to the lack of reporting by the articles. Only nine articles provided information on the health services 
Table I Participant characteristics

\begin{tabular}{|c|c|c|}
\hline Characteristics & $\begin{array}{l}\text { Number of } \\
\text { participants } \\
(\%)\end{array}$ & $\begin{array}{l}\text { Number of } \\
\text { reporting } \\
\text { articles } \\
\end{array}$ \\
\hline \multicolumn{3}{|l|}{ Parent } \\
\hline $\begin{array}{l}\text { Focus group/semi-structured } \\
\text { interview }\end{array}$ & $747(44.6)$ & \\
\hline Open-ended questionnaire & $928(55.4)$ & \\
\hline Total & $\mathrm{I}, 675$ & 50 \\
\hline \multicolumn{3}{|l|}{ Child } \\
\hline Total & 1,616 & 50 \\
\hline \multicolumn{3}{|l|}{ Age range (years) } \\
\hline \multicolumn{3}{|l|}{ Parent } \\
\hline $22-83$ & $\mathrm{I}, 675(100.0)$ & 50 \\
\hline \multicolumn{3}{|l|}{ Child } \\
\hline $1-12$ & I,586 (98.0) & 50 \\
\hline$>12$ & $30(2.0)$ & \\
\hline \multicolumn{3}{|l|}{ Sex } \\
\hline \multicolumn{3}{|l|}{ Parent } \\
\hline Male & $288(17.3)$ & 49 \\
\hline Female & I,379 (82.7) & \\
\hline \multicolumn{3}{|l|}{ Child } \\
\hline Male & $\mathrm{I}, 000(81.0)$ & 28 \\
\hline Female & $234(19.0)$ & \\
\hline \multicolumn{3}{|l|}{ Education level } \\
\hline Primary & $13(1.6)$ & 17 \\
\hline Secondary & $308(37.6)$ & \\
\hline College & $107(13.0)$ & \\
\hline Undergraduate & $253(30.8)$ & \\
\hline Postgraduate & $136(16.6)$ & \\
\hline Unknown & $3(0.4)$ & \\
\hline \multicolumn{3}{|l|}{ Ethnicity } \\
\hline White & $84(35.4)$ & 16 \\
\hline Caucasian & $65(27.4)$ & \\
\hline Latino/Hispanic & $39(16.5)$ & \\
\hline Asian & $30(12.6)$ & \\
\hline African-American & $13(5.5)$ & \\
\hline Unknown & $7(3.0)$ & \\
\hline \multicolumn{3}{|l|}{ Living community } \\
\hline Urban & $44(34.1)$ & 8 \\
\hline Metropolitan & $50(38.8)$ & \\
\hline Regional & II (8.5) & \\
\hline Rural & $24(18.6)$ & \\
\hline
\end{tabular}

received, comprising Speech Language Pathology, Applied Behavioural Analysis, Early Intensive Behavioural Intervention, Sensory Integration Training, and Treatment and Education of Autistic and Related Communication Handicapped Children.

\section{Thematic analysis}

Four core themes and 17 domains were developed from the synthesis encompassing all thoughts, emotions, and experiences commonly expressed by parents regarding the processes involved when dealing with children with autism. The development of themes and domains and the number of articles contributing to each theme are presented in Figure 2 (Table 2 for the breakdown of articles into themes).

\section{The parent}

\section{Receiving the diagnosis}

Upon receiving the diagnosis of autism, parents had a mostly negative emotional response; expressing shock, despair, and devastation. Feelings of anger were especially common due to resentment.

There's an incredible anger... against people who dare to suggest that everything is hopeless and that this is a complete and utter nightmare. ${ }^{32}$

Anger was also directed toward health care professionals.

Why didn't people take my concerns seriously? Why didn't the doctor believe what I said and help me sooner? ${ }^{33}$

In a number of studies, parents initially denied the diagnosis, due to a lack of understanding of the disorder, doubt on the diagnosis given, or disbelief that such a thing would ever occur to their child. ${ }^{33-36}$ Several parents felt guilty and blamed themselves for the inheritance, the lack of care, or for vaccinating their child. ${ }^{15,36-38}$ Others felt hopeless in their inability to help their children. ${ }^{15,33,39}$ However, there were some positive emotional responses, involving feelings of relief or vindication upon hearing the diagnosis. This was because parents' concerns were finally addressed and parents knew what they were dealing with. Receiving the diagnosis allowed parents to begin coping with it and to reconcile any guilt or self-blame for attributing the child's behavior to bad parenting. ${ }^{40,41}$

\section{The difficult child}

Parenting a child with autism was depicted as difficult due to challenging behaviors that caused increased levels of stress and impacted upon parents' daily lives. Uncontrollable and unpredictable tantrums and aggression were commonly experienced in response to changes in routine or the environment characteristic of autism. Aggressive behaviors caused damage to the house ${ }^{42}$ with parents constantly burdened with the costs of replacing damaged items. ${ }^{43}$ Violence was also reported by several parents, either toward siblings or the parents' themselves. ${ }^{35,42}$ These behaviors brought emotional and physical consequences to parents, ${ }^{42}$ in addition to the lack of sleep to meet the child's demands. 

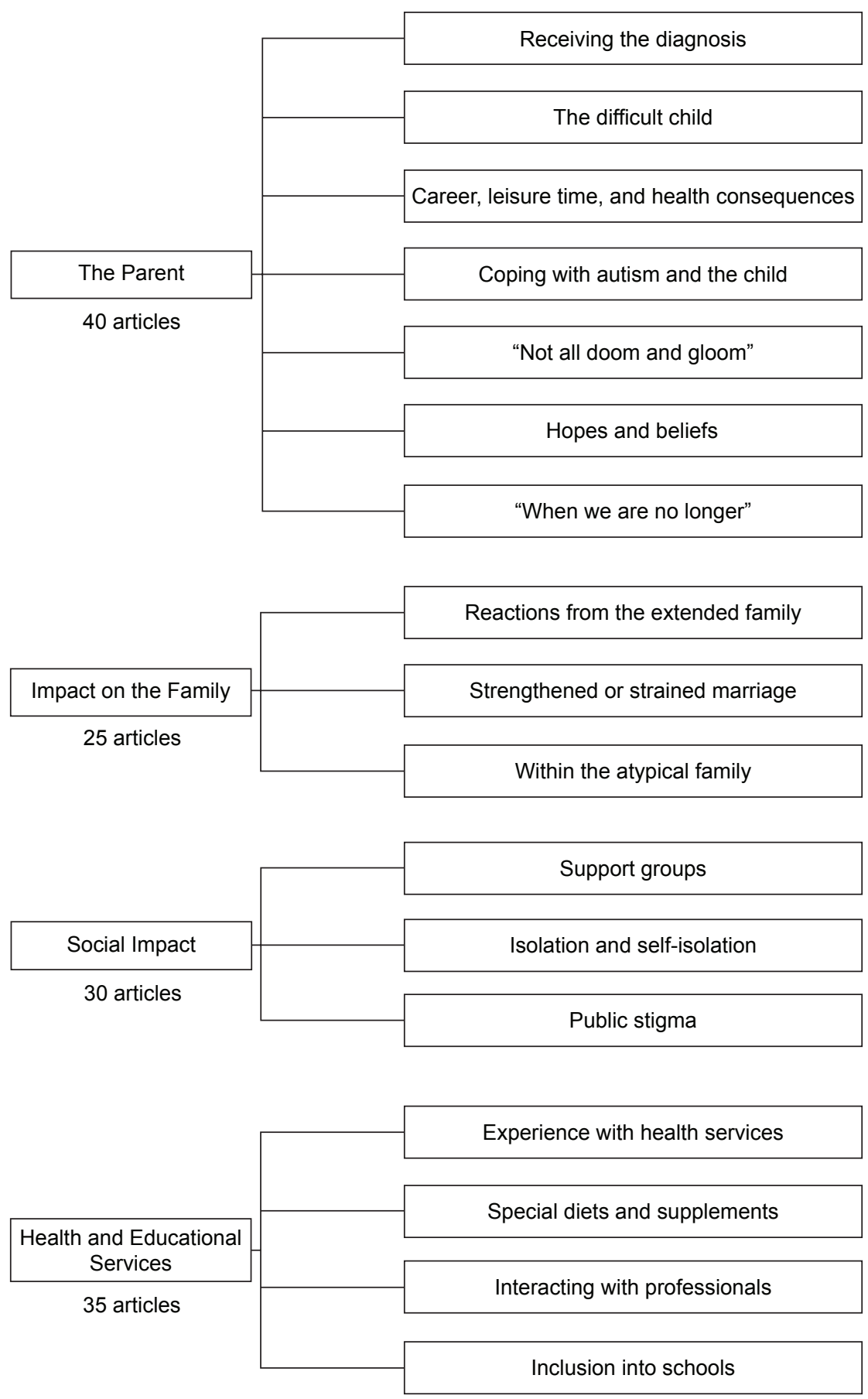

Figure 2 Development of core themes and domains.

If the child wants to get into the car and have a ride, you must do it, otherwise he gets ill-tempered, yells at midnight [...] I had to drive him around from 01 till 04 in the morning, then I slept for $2-3 \mathrm{~h}$ and went to work. ${ }^{35}$

These challenging behaviors were perceived to occur due to sensory hypersensitivities, such as to the sound of dogs barking, loud sounds, and strong sunlight. Additionally, many had problems with self-care due to negative hypersensitivities, such as bathing, brushing the teeth, haircuts, and nail trimming. ${ }^{44,45}$ Idiosyncratic food sensitivities were another problematic feature, causing dinner time to be particularly challenging, ${ }^{46}$ as the child's sensitivities to food textures resulted in food restrictions. Behaviors, such as "meltdowns", "g5agging", ${ }^{45,46}$ "walking away", ${ }^{46}$ and food getting "shoved off onto the floor", ${ }^{46}$ were described with regard to food the child refused to eat. This affected 
Table 2 Breakdown of articles into themes

\begin{tabular}{|c|c|c|}
\hline Themes & $\begin{array}{l}\text { Number } \\
\text { of articles }\end{array}$ & References \\
\hline The Parent & 40 & 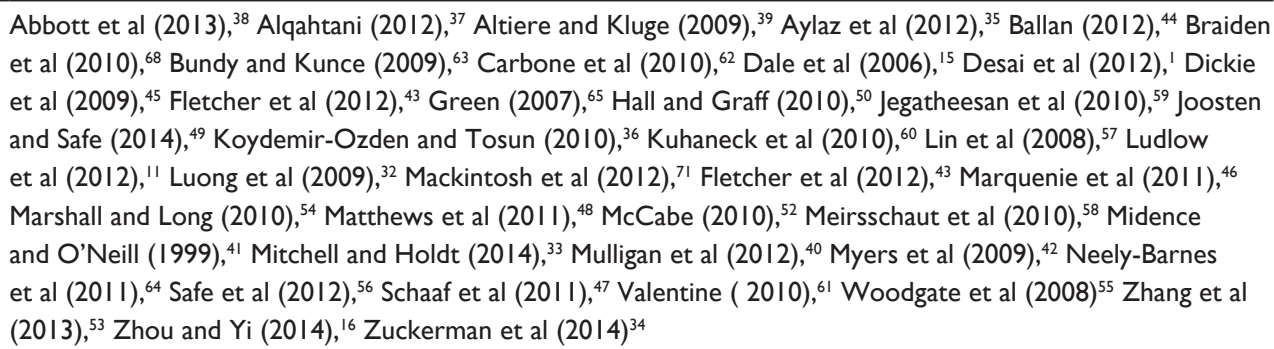 \\
\hline $\begin{array}{l}\text { Impact on the } \\
\text { Family }\end{array}$ & 25 & 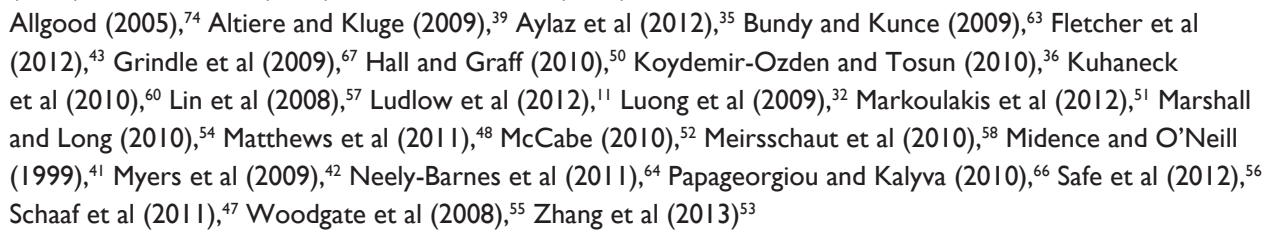 \\
\hline Social Impact & 30 & 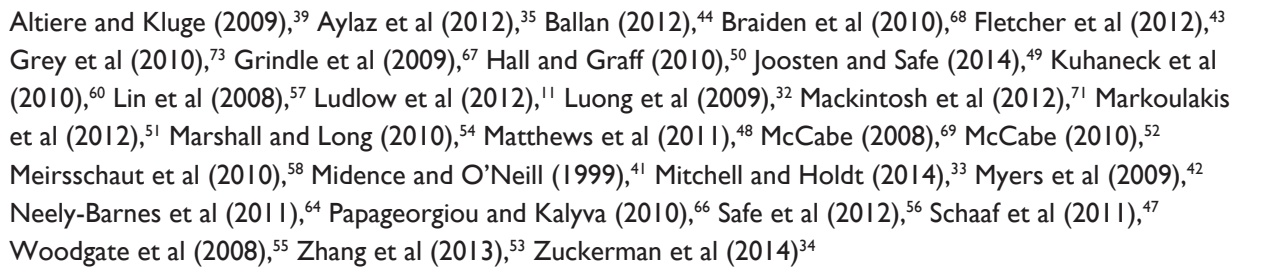 \\
\hline Health and & 35 & Abbott et al (20I3), ${ }^{38}$ Allgood (2005), ${ }^{74}$ Alqahtani (20I2), ${ }^{37}$ Altiere and Kluge (2009), ${ }^{39}$ Auert et al (20I2), ${ }^{77}$ \\
\hline Educational Services & & 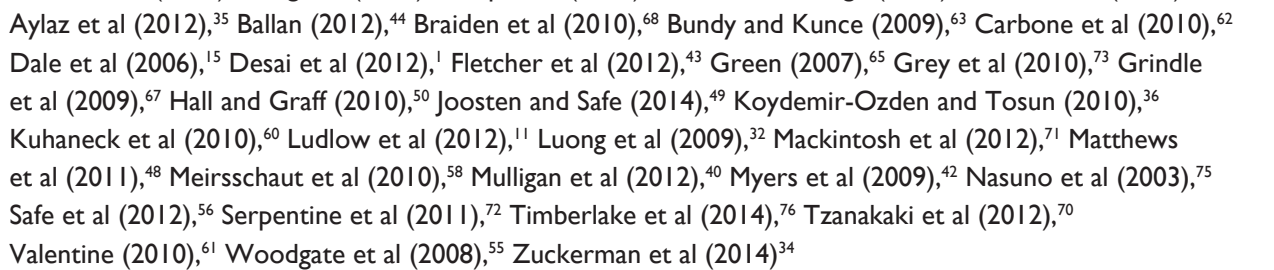 \\
\hline
\end{tabular}

nutrition and the family's choice of food, forcing mothers to cook multiple meals to accommodate the family's and the child's mealtime needs. ${ }^{46}$ Also, due to the child's disruptive behavior during mealtimes, they were often exempted from eating with the family. ${ }^{46,47}$

\section{Career, leisure time, and health consequences}

Due to the high demands associated with taking care of the child, the personal lives of parents were affected in terms of their career, leisure time, and health. Many mothers described having to quit their jobs or giving up career opportunities to care for the child and take them for treatment. ${ }^{32,33,43,48}$ The child's inability to withstand changes in work routines and lack of support, further restricted parents' ability to work. ${ }^{11,42,43,49}$ Consequently, the need for mothers to stay home restricted their ability to have a desired career, resulting in fathers being the only breadwinners of the family. ${ }^{42}$ A considerable amount of family finances were spent on expensive treatments and to a relatively lesser extent on the cost of damages caused by disruptive behaviors, as well as the costs of general care not required by a typical child. ${ }^{35,43}$ In addition to these financial strains, inaccessibility or insufficiency of financial support was also reported. ${ }^{36,50,51}$ Indeed, these financial problems increased the level of stress and worry in parents, with several paying for treatments out-of-pocket or taking multiple loans..$^{39,43}$ One parent in a study went to the extent of mortgaging the house to pay for treatments. ${ }^{39}$

In contrast to parents who gave up their career, some felt that having a career provided an escape route, a sense of identity, or finances to pay for treatments, and strived to maintain a balance. Some found new career opportunities within the autism community, such as becoming a specialeducation teacher. ${ }^{42,51,53,54}$

On the other hand, parents' leisure time became filled with the needs of the child, with little time for themselves; resulting in constant states of fatigue. ${ }^{35}$ Free time was achieved by waking up earlier, during school hours when the child was not at home or after the child fell asleep, in an effort to manage their level of stress and well-being..$^{32,43,49,55}$ Parents' health was 
also affected, either due to the high demands of taking care of the child or due to parents disregarding their own health for their children, resulting in sleep deprivation, insomnia, and low energy levels. ${ }^{42,43,48,56}$ In other cases, however, parents' health improved as they became more aware of the importance of their own health in caring for their child. ${ }^{48}$

\section{Coping with autism and the child}

In order to cope with autism, several coping strategies were adopted. Parents described accepting the diagnosis and their child for who they were and focusing on what could be done. 15,32,49,55-57 The terms "doing all you can"55 and "never give up" ${ }^{50}$ depicted the pragmatism and perseverance parents had as they channeled all their strength and time to improve the child's condition. ${ }^{57-59}$

Parents strived to improve their knowledge on autism by reading books, conversing with other parents, and surfing the Internet to obtain information. ${ }^{36,50,55,57,58}$ Parents were also more proactive when it came to the child's treatment by sourcing for treatment and would try anything that would help their child. ${ }^{32,55,61,62}$

I want my child to improve. He needs more help. He needs more therapy. That was why I put him on the after school program. I learned from watching the therapist, too...I also put him on a special supplements therapy. I think it might help. ${ }^{32}$

The sense of hope experienced when their child improved also helped parents cope. ${ }^{36,50}$ At the same time, however, they acknowledged that not everything could be changed and had to let go of certain expectations from/of the child. ${ }^{54,55}$ Others turned toward spirituality and religion to preserve their sense of hope, achieved by praying or reciting the Al-Quran. ${ }^{32,37,53}$ Nevertheless, not all parents coped effectively. After some time, several were still in denial, which affected their ability to advocate for the child. ${ }^{16,36,39}$

We seem to have been getting advice from here there and everywhere...It was just so mind boggling at the time. I was still dealing with the fact that we had this horrible word now labelling our son. ${ }^{61}$

Parents from several studies indicated that they still "grieve the child that I once imagined", ${ }^{42}$ felt "depressed", 39,42,48 and portrayed having a child with autism as a nightmare. ${ }^{11}$ Several also felt hopeless and lacked confidence in their parenting, ${ }^{15,63}$ stating that "No matter how hard we try, we cannot beat destiny". ${ }^{42}$
With regard to the child's difficult behaviors, parents learned to deal with the child's needs and behaviors with time. Parenting strategies taken on by many included hypervigilance of the environment and the child's responses, anticipation of difficulties, preplanning of responses, and preparation of the child to prevent challenging behaviors from occurring when switching between environments. ${ }^{47,53,55,56}$ Within these strategies, adopting a fixed routine, role playing, and providing a warning were considered effective to cope with sensory hypersensitivities or environmental changes. ${ }^{44,47,54,60}$

Adjusting household activities to avoid negative sensory reactions from the child were also carried out, for example, by using a broom instead of a vacuum or only using the vacuum in the absence of the child. ${ }^{45,47}$ These strategies reduced stress levels in both the parent and the child, in addition to preventing disruptive behaviors. ${ }^{56,60}$ However, the constant need to be vigilant caused increased levels of stress and exhaustion. ${ }^{54,56}$ The need to always plan ahead also resulted in inflexibility. ${ }^{43,58}$ In terms of the child's mood and level of stress, parents in one study perceived that their mood affected their child's symptoms, whereby when parents were in a positive mood, so too were their children, with the children's symptoms noticeably improving. ${ }^{16}$

When I was in a low mood his symptoms became severe,

while when I was relaxed he performed relatively well. ${ }^{16}$

Thus, parents in this study cited the importance of an emotional relationship between the parent and the child for the child's development. ${ }^{16}$

\section{Not all doom and gloom}

Despite having challenges, parents still expressed that they found joy and felt blessed in raising a child with autism. ${ }^{11,39,41,54}$ Joy was also expressed when the child achieved a developmental milestone or showed affection to parents. ${ }^{39,51}$

...sometimes [Daniel] will come in and all of a sudden say "Mummy I love you"; [Chris] do a puzzle and I'm just amazed at how intelligent he really is. ${ }^{56}$

Parents perceived their children to be affectionate, intelligent, and possess a sense of humor, despite having autism. Unconditional love for their child was also continuously expressed. ${ }^{35}$

As far as I am concerned, she is my blood and flesh. Autism is an integral part of her, it is not a problem anymore. ${ }^{41}$ 
Parents in one study also stated that their child saved them from illnesses due to their child's need for them. ${ }^{64}$ Moreover, parents stated that having a child with autism changed their perspective of life and made them more appreciative of it. ${ }^{42,53,60}$ Parents also expressed that they became more sensitive, understanding, and less judgmental toward people around them..$^{39,42,51,53,55}$ Being more compassionate, patient, and sociable were also characteristics gained from raising a child with autism..$^{39,51,53}$ Indeed, the sense of achievement from raising a child with autism boosted their self-confidence..$^{53}$

\section{Hopes and beliefs}

Certain beliefs were held by parents regarding the label of autism. Many parents believed that symptoms would subside, ${ }^{1}$ hoped for a cure with medical advancements, ${ }^{1,15,63-65}$ or that the child would eventually outgrow the disorder. ${ }^{15}$ Others believed that their child would continue to develop, even though a cure could not be achieved. ${ }^{15,55,64}$

Several attributed the label of autism to fate or to a spiritual or religious belief, stating that "There are no coincidences", ${ }^{4}$ or "God gave him to us", ${ }^{39}$ believing that they were meant to be parents of children with autism or that they were capable to care for one..$^{32,54,59}$ Other religious beliefs were that the child was in their last rebirth, that parents were indebted to the child in their past lives, ${ }^{32,59}$ that God would help them, ${ }^{42,53,54}$ or that Allah was testing them. ${ }^{59}$

\section{When we are no longer}

With the child's poor development, parents expressed uncertainty over their child's future. The high dependency of these children on parents repeatedly raised concerns, regarding the time when they are no longer able to care for the child. Concerns included the child's ability to be independent, to achieve the most basic survival skills, and self-care.

I say to my child: My dear, you will put on your pyjamas, you will eat by yourself, I will die one day, if you are left alone, you will have to take care of yourself, you have to survive. ${ }^{35}$

The child's safety and well-being were also of concern. ${ }^{32,35,42,44}$ Several parents wanted a normal life for their child and were troubled with the child's inability to secure a job, integrate into society, or get married. ${ }^{41}$

Some parents perceived that education and social inclusion would help their children achieve these future expectations, ${ }^{1,41,52,59}$ but at the same time were concerned with the child's inability to cope with it. ${ }^{1,39,44,63}$ Concerns were dealt with by saving finances and trusting siblings to care for the child in the future. Only a minority were confident of their child's future, stating that they had high hopes for their future. ${ }^{39,59}$

\section{Impact on the family Reactions from the extended family}

In a number of cases, the extended family was perceived to be supportive, providing both emotional and practical support. ${ }^{11,42,48,57}$ Mothers especially valued this support, as it helped them cope with the label of autism and the demands of care, as well as brought the family closer. ${ }^{36,39,42}$

At the beginning I felt very sad, but when I found that my mother-in-law would help me, I gradually came to feel that his condition is not that serious. ${ }^{57}$

Conversely, many parents stated that family members did not understand the disorder, even if they accepted the diagnosis, and thus could not provide the needed support. ${ }^{39,55,56,66}$ Denial was common, with grandparents blaming the child's disruptive behavior on bad parenting or even blaming them for the disorder. ${ }^{11,42,64}$

Her illness has caused many rows within the family as they doubt the diagnosis and just think she's in need of a smack. $^{42}$

A few resented the lack of support from relatives living in the vicinity, leaving parents with a sense of isolation. ${ }^{48} \mathrm{In}$ more severe cases, the family confronted with autism was rejected ${ }^{39,66}$ and was not included in family gatherings. ${ }^{42}$

\section{Strengthened or strained marriage}

Having a child with autism was observed to result in either a strained or a strengthened marriage. In the latter, parents expressed that the situation brought their family together. ${ }^{48}$ Parents set aside their different perspectives, argued less, and instead focused on their child. ${ }^{51,53,55}$ Having a good marital relationship was viewed as essential as it allowed for respite care and provided emotional and practical support. On the other hand, some parents revealed that their marriage became strained, sometimes to the point of divorce. ${ }^{36,58}$ Reasons for the strain included loss of time spent together due to the high demands of taking care of the child, ${ }^{35,42,48,67}$ disagreements regarding parenting, ${ }^{35,36,48}$ and blaming each other for the disorder. ${ }^{42,58}$ In several cases, mothers felt unsupported 
by their spouse as they were left to deal with the child themselves. ${ }^{52}$

\section{Within the atypical family}

Parents observed that it was difficult to perform typical family activities due to the negative impact of the child's behavior. $^{47,58,63}$

We can't go to the movies. We don't go to the circus, a play, a family party that was not in a particular setting. We can't go to restaurants other than McDonalds. ${ }^{47}$

Consequently, the times spent together as a family were reported to be scarce, with one parent staying with the child with autism while the other spent time with the typical sibling; in an effort to meet the special and normal needs of both their children. ${ }^{42,47}$ Parents also expressed concern with regard to the siblings of a child with autism. A large number of parents felt worried and guilty about the neglect in attention that siblings faced, as it was focused instead on the child with autism. ${ }^{36,43,47,50,58}$

I feel a lot of times his older brother gets the short end of the stick yet I don't know how to make it right and I don't think I can ever do so. ${ }^{42}$

Some parents also stated that siblings had made comments about the lack of care given to them, such as "it's always about [my brother with autism]," 47 and became jealous. ${ }^{35,39,47}$ In some instances, however, siblings were accepting and helped with the care of the child with autism. ${ }^{35,39}$ This prompted parents to claim that the child with autism increased their opportunity to spend time with all their kids ${ }^{39}$ and brought the family together. ${ }^{41}$

\section{Social impact}

\section{Support groups}

Not all parents perceived that support groups were available either due to the lack of awareness about autism in society or because parents were uninformed of such groups. ${ }^{33,68}$ Support groups were also perceived to be inaccessible, with parents citing that support was given based on the severity of the child's autism. ${ }^{11}$ A few parents also felt that support groups did not meet their needs. Reasons for the perceived lack of benefit include busy schedules, ${ }^{32}$ a lack of desire to hear or share one's problems, ${ }^{32}$ a lack of desire to center one's life around autism, ${ }^{56}$ and the perceived lack of sincere emotional and practical support. ${ }^{49,60}$

Conversely, parents who participated in support groups largely perceived that participation was beneficial.
Parents valued the emotional and practical support provided by other parents in the same boat and their chance to share problems not understood by parents of a typical family. ${ }^{11,53,56,69}$

Because you live it, then you understand it, and you identify

with it...you can be each other's support. ${ }^{56}$

Furthermore, parents appreciated learning from other parents how to cope with, and manage their child through the advice received or through observation. ${ }^{69}$ These benefits instilled confidence in parents about their parenting, provided a sense of hope or relief, ${ }^{11,53,69}$ and introduced them to a new social circle. ${ }^{39,51}$ Parents also acted as advocates for others who have a child with autism with the intention of either providing help, receiving help in return, or creating a better awareness of the disorder. . $^{5,51,53,54,57}$

\section{Isolation and self-isolation}

Isolation was a common experience, as friends avoided parents, thus leaving them with a sense of diminished support. ${ }^{42}$ This was seen to be due to the child's difficult behavior, which friends were not able to cope with. ${ }^{43,56}$ Others felt isolated due to the lack of time to participate in social activities in order to care for the child or work. ${ }^{48,52}$ In contrast, worry that the child would not be understood or would cause trouble, discouraged parents from visiting friends or inviting guests to their house. ${ }^{11,35,39,42,47}$

You can't go and visit your friends, you can't admit any-

body; rather than coming back in stress I choose not to go

on a visit. ${ }^{35}$

One parent in a study also did away with friends that reacted adversely to the child. ${ }^{39}$ However, not all parents felt isolated from their social circle. In some instances, friends and colleagues accepted the child and supported parents by offering a supportive ear and giving advice. Employers also allowed time off work to meet the child's needs. ${ }^{53,57,64,66}$ The parents highly valued the support given, underlining its importance in parents' ability to cope with the child. ${ }^{39,48}$

\section{Public stigma}

Going out was perceived to be difficult due to judgment from the general public in the form of "dirty looks", 39 "staring," "tutting," "49,56 and avoidance. ${ }^{11,43,66}$ Direct criticisms regarding the child and their "bad parenting" were also experienced. ${ }^{10,49}$ "They said we shouldn't go out if we can't control our child." 35 
This occurred due to misinterpretation of tantrums that occurred in public as misbehavior, triggering embarrassment, sadness, anger, and disbelief in parents. ${ }^{11,42,49,64}$ Many felt that the lack of awareness and understanding about autism were contributors to this stigma. ${ }^{34,44,49,55,56,58,66}$ A number of them also mentioned that stigma was due to the "normal" appearance of the child, whereas the disorder was invisible to the eye..$^{52,64}$

If he were physically handicapped people would understand and would be kind. Because he looks like a normal child, people don't see the autism and don't understand. ${ }^{41}$

Stigma was dealt with in several ways. Some parents avoided the consequences of going out in public and stayed home. Several ignored the comments. ${ }^{35,42}$ Likewise, a number of them acted by educating others, ${ }^{49,51,55,64}$ while a few acted defensively, confronting negative comments. ${ }^{56}$

\section{Health and educational services}

\section{Experience with health services}

Health services accessed by parents included diagnostic and treatment services. The lack of transparency about the diagnostic process, along with the long wait to obtain a diagnosis, resulted in frustration and anger. ${ }^{34,38,40}$ Parents felt overwhelmed and exhausted with the feedback session that followed the diagnosis, describing it as an overload of information in trying to understand the assessment and the disorder. ${ }^{38,40,68}$ Provision of written information proved to be useful, but several parents still had difficulty comprehending the information. ${ }^{38,68}$ Alternatively, parents cited that a feedback session as a follow-up would be useful in reviewing the diagnosis, as it gave parents time for the diagnosis to sink in. ${ }^{40,58}$

After receiving the diagnosis, several parents expressed anger and isolation due to the lack of support from health care professionals in informing them of available treatments, forcing them to source for it themselves. ${ }^{15,62,68,70}$ Some even spoke of being informed that nothing was available. ${ }^{70,71}$ Thus, parents mentioned that information on resources was obtained mainly from other parents or from public resources. ${ }^{62,70,72}$ Furthermore, treatment services and resources were said to be limited, ${ }^{40,56}$ had strict admission criteria, ${ }^{40}$ and had long waiting lists. ${ }^{40}$ This left parents feeling frustrated as they fought to obtain services. ${ }^{42,56,60,73}$

Affordability was another issue, with expensive treatments and scarcity in funding or insurance coverage. $49,50,61,67,71$ As a result, parents paid for treatments on their own, $43,50,70,73$ selected alternative treatments that were not optimal for their child, ${ }^{43}$ or had to do without treatment. ${ }^{71}$ Only parents from two studies mentioned that funding were available to them..$^{70,73}$

...the price is outrageous and we could not afford it. So for a little while, for about six months [child's name] was not on any program at all. ${ }^{61}$

In relation to behavioral or educational therapies, positive aspects mentioned included improvements in the child's behavior and development, such as reduced difficult behaviors and improved language and social skills. ${ }^{67,71,74}$ Indeed, parents had expectations of improved tolerability to negative sensory experiences, improved food selectivity, a possibility for integration into mainstream schools, or a cure of autism. ${ }^{65,70,72}$ Parents' involvement in the therapy was also perceived to be beneficial, stating that they could learn skills to manage the child and understood their child better. ${ }^{74-76}$ Concurrently, having a therapist at home allowed for respite care, as it gave parents free time off from their child. ${ }^{67,76}$

Nevertheless, several drawbacks were mentioned concerning the therapy used. First, some parents expressed that they could not understand the aspects of therapy or that they were difficult to implement, although some perceived otherwise. ${ }^{40,65,70,75}$ Also, not all parents perceived that the therapy they used was effective, stating that the therapy was unsuitable for the child, was lacking in intensity, or was slow in the child's rate of improvement. ${ }^{70-72}$ Time demands associated with conducting home-based therapies were exhausting, as parents were also required to tend to other commitments. ${ }^{56}$ Additionally, parents expressed that there was a limited number of therapists ${ }^{71,73,75}$ and disliked the high turnover of therapists. ${ }^{56}$

I have to repeat the "instructions on how to operate my son" a million times. We all know how important routine is for a child like my son, yet, life unavoidably brings change. I would like more consistency in my son's treatment. ${ }^{71}$

\section{Special diets and supplements}

Only five of the included studies provided parents' opinions on the use of special diets or supplements for autism. Perceived positive effects as a result of using casein- or gluten-free diets or supplements included improved physical health, improved concentration that brought about better learning abilities, and a calmer behavior. ${ }^{43,65,70}$ However, there were disadvantages cited such as high costs, further food restrictions of the child with special diets, and difficulty in getting the child to take supplements. ${ }^{43,70}$ Some 
parents also observed that while special diets or supplements were not effective, they may work on other children with autism. ${ }^{37,65}$

\section{Interacting with professionals}

With regard to health care professionals, characteristics greatly valued by parents during the delivery of the diagnosis included being supportive, compassionate, and sensitive, in putting parents at ease. ${ }^{38,40}$ Parents appreciated to be given time to absorb and be directed to focus on present issues, when the diagnosis of autism overwhelmed them with emotions and uncertainties of the future. ${ }^{38}$ In the same vein, parents wanted an honest and transparent discussion of their child's prognosis from the health care professional but also valued optimism about their child and parenting as it preserved their sense of hope. ${ }^{38,40,68}$

Nobody wants to feel like they've just been given the death sentence for their child. But at the same time you desperately want to feel like there's hope...that there's room for improvement and that there's stuff that can be done..$^{40}$

For health care professionals involved in behavioral or educational therapies, personal qualities sought by parents included being able to interact with the child at a personal level, being empathetic, passionate, and showing professionalism in handling the child. ${ }^{71,76,77}$ Parents desired adequate communication with health care professionals with regard to the child's treatment in order to be informed and involved, as it enabled them to cope and have confidence with the child's care. ${ }^{44,77}$

Experiences that caused frustration were when professionals involved in a home-based therapy were unreliable due to unpunctuality, requested to leave early, lacked professionalism, or lacked the appropriate skills and knowledge about autism to provide therapy. ${ }^{50,55,67,71}$ Many parents also mentioned that health care professionals were dismissive of parents' concerns. ${ }^{44,62}$ This resulted in feelings of disrespect and disempowerment, as parents were not regarded as the experts of their child. ${ }^{62,71}$ As for education providers, some parents stated that school teachers had limited knowledge about autism and its associated behaviors, thus perceiving that the child was misbehaving. ${ }^{56,73}$ This resulted in a diminished trust in teachers, as parents saw teachers as untrained and uninformed about autism. ${ }^{50}$ Similarly, parents in one study remarked that the teachers' attitudes and their willingness to understand the child were important to provide education to their child. ${ }^{73}$

\section{Inclusion into schools}

Several perspectives were identified with regard to children's placement into special or mainstream schools. Similar to parents' opinion about being informed and involved in the child's treatment and prognosis, parents wanted to be informed about their child's education program as it gave parents a sense of control. ${ }^{77}$ Involvement with the child's education was also desired, achieved by attending school meetings; and citing that schools should provide children with activities that parents can complete with them at home. ${ }^{36,50,73}$

However, only a few expressed satisfaction with their child's inclusion into schools, stating reasons such as the school's good efforts and attitudes in helping their child, the child's benefits in learning, and in gaining friends. ${ }^{36,73}$ Most expressed dissatisfaction, blaming the poor capabilities of the school in accommodating the child's needs and in providing effective education to children with autism. ${ }^{11,35,71}$ The lack of knowledge and understanding of autism were perceived to be the reasons for the school's lack of efficiency. ${ }^{71}$

Schools don't know how to modify curriculum for an autis-

tic child in the full inclusion environment and don't know enough about autism and how they learn. ${ }^{71}$

Likewise, parents wanted a written plan and formal assessments to be in place for the child's inclusion into the school and wanted there to be individual meetings with children to help them progress and learn. ${ }^{36,73}$

\section{Discussion}

This meta-synthesis explored the perspectives of parents in raising a child with autism during their childhood period. Parents were found to experience multiple challenges in different aspects of care, thus occupying different themes or domains simultaneously. The experiences compiled represent the dynamic lives of parents of children with autism and portray the overall difficulties, or benefits, of having a child with autism.

\section{Psychological impact}

The first theme described the psychological impact parents experienced as a result of receiving a diagnosis of autism and from having to face and deal with the difficult behaviors of the child. The lives of parents were discovered to be affected by autism in terms of their health, financial career, and leisure activities. The growth and adaptation parents underwent as they raised their child were also highlighted, along with their thoughts with regard to the child's capacity to function as an independent individual in the future. The results of the 
synthesis showed that most parents lowered their future expectations of the child, wishing for the child to attain at least the basic skills required to survive. This may suggest parents' acceptance of the child's lack of normalcy and of the child's future.

Following the myriad of positive or negative emotions experienced at diagnosis, parents were found to adopt several coping strategies. With time, many parents described acceptance and developed a problem-focused strategy, or "engagement" as described by Benson; ${ }^{78}$ to cope with the disorder. A pragmatic attitude was observed in parents, whereby parents worked to increase their knowledge on autism and searched for treatments to see their child improve. Indeed, studies have shown that adopting a problem-focused strategy improves parents' psychological well-being and parenting efficacy. ${ }^{79-81}$ This could be attributed to parents becoming enabled to advocate for their child with the knowledge gained, and which subsequently reduces feelings of hopelessness in helping their child improve. Thus, equipping parents with information and resources after receiving the diagnosis can be useful in giving parents a sense of control and empowering them to advocate for their child at a faster rate.

Nevertheless, an increased level of stress was mentioned as a psychological outcome as parents struggled to manage the disruptive behaviors of the child. Consistent with the literature, studies have shown that the child's difficult behaviors were significantly associated with increased parental stress levels and psychological well-being such as depression and anxiety. ${ }^{82-84}$ In contrast, some studies stated that the child's difficult behaviors predicted stress levels but not psychological well-being ${ }^{17,24,85}$ or that only certain aspects of the child's behavior contributed to stress levels. ${ }^{17,86}$

These findings could indicate that the psychological well-being of parents may not only be directly attributed to stress-causing behaviors but also to parents' definitions of the behaviors perceived to be difficult. Thus, having positive perceptions about the child may preserve the psychological well-being of parents, despite the diagnosis of autism, ${ }^{87-89}$ such as the joy and love parents expressed for their child in the synthesized results. It might therefore be of benefit in health care practices to help parents redefine their perceptions of the child to a positive one, in order to cope with the child - an approach known as positive coping. ${ }^{88}$

In the same vein, parents mentioned that the behavior of the child was affected by the parents' mood. Two studies showed similar findings, whereby the mother's criticism of the child worsened behaviors in a study by Baker et al; ${ }^{90}$ while the mother's positive affection to the child was associated with reduced repetitive behaviors in a study by Smith et al. ${ }^{91}$ These findings imply a possible reciprocal relationship between the child's behavior and the parents' stress levels and well-being. Hence, it may be important for health care professionals to not just focus on managing the child's behavior but also reinforce the need to guide parents in improving their mood so as to improve the child's stresscausing behaviors.

On the other hand, to meet the demands of childcare and to take the child for treatments, the ability of mothers' to work or have free time for themselves was reported to be affected. As a result, there is little respite care for mothers, and the constant need to face their child can have an impact on stress levels and their psychological well-being despite adopting a problem-focused strategy. ${ }^{79,81,92}$ Furthermore even after some time, not all parents were able to accept the diagnosis, expressing negative comments or emotions about their child or parenting, indicating maladaptive coping. Conversely, indicative of positive coping, some parents described becoming more sensitive and appreciative of life as a result of raising a child with autism. ${ }^{89}$

Parents from this meta-synthesis were also observed to hold certain beliefs toward autism. Of note is the hope or belief that autism would one day be cured. Although this belief may act as a buffer for parents to cope, it is important to note that there is no cure for autism. ${ }^{12}$ These beliefs should not be left alone as it may lead to false hopes or a continuous denial of the diagnosis, possibly leading to maladaptation to the disorder and impairment in the family's quality of life. Thus relevant health care professionals such as counselors need to ensure that parents are aware of this fact and help them overcome the psychological impact of the diagnosis while guiding them toward acceptance.

\section{Family life and relationships}

The family life surrounding the child with autism was affected, from within the nuclear family to the extended family. The findings illustrate that the family caring for a child with autism differs greatly from a typical family. This was mainly due to the child's intolerability to changes or sensory hypersensitivities that impeded the family from carrying out normal family activities. In turn, parents described that family activities were adapted to the needs of the child with autism or that they did their best to perform activities similar to that of typical ones in order to meet the needs of their typical children.

Spousal and extended family relationships tended to either improve or deteriorate. In an improved marital 
relationship, support for each other in advocating for the child, both emotionally and practically, was evident and was seen as a valuable source for coping. The value parents held for these forms of supports from extended families was also observed. The benefits of having family support are supported by quantitative studies, whereby increased family support has been shown to be associated with decreased stress levels or improved psychological well-being in parents. ${ }^{93-95}$

On the flip side, parents, especially mothers who described that spousal relationships worsened, attributed it to the needs of the child that was time and energy consuming, the blame on one another for the diagnosis, or the poor support from husbands. However so, the strains within the family should not be overlooked and instead integrated into practice as it may impact on parents' marital satisfaction, psychological well-being, and overall family's quality of life.

\section{Social experiences}

With regard to support groups, several parents mentioned that support groups were inaccessible. This may be due to the professional's lack of knowledge, failure to communicate, or by the general lack of such services in society, although which of these precedes in significance requires more investigation. Nevertheless, most parents who accessed support groups were observed to cite more benefits than disadvantages. Such benefits included providing parents with encouragement and a sense of hope in raising their child. It also provided parents with a new social circle in the midst of isolation from friends and colleagues. The benefits of social support are statistically supported, with studies showing a positive impact on parents' stress levels, ${ }^{96}$ mood, ${ }^{81}$ and family's quality of life ${ }^{80}$ Whereas, the lack of social support has been associated with increased stress levels ${ }^{96}$ and perceived negative impact of autism. ${ }^{97}$

There is also the issue of stigma from the public, which was strongly perceived to be due to the normal appearance of the child. This then resulted in the public's misinterpretation of the child's behavior attributable to autism, as misbehavior. To overcome this, policy development can be aimed at increasing the awareness on autism, not only to the general public to reduce stigma but also to health care providers on the importance of communicating the availability and benefits of support groups to parents in order to reduce the judgment and isolation felt by them.

\section{Professional support and services}

This final theme encompassed the experiences and expectations of parents with services and professionals in relation to treatment or educational interventions. First, the myriad of emotions experienced upon diagnosis followed immediately by a feedback session were overwhelming for parents. Concurring with the parents' suggestions, ${ }^{40,58}$ providing information as a follow-up session some time after the diagnosis may therefore be useful, allowing parents to better comprehend the session. However, the time span between diagnosis and follow-up should not be too long. This is because the support provided by health care professionals would be important at this phase, as parents are found to be at a loss as to what to do, which can lead to maladaptation. Thus, the continuity of care following diagnosis would be a valuable support in order to lead parents in the right direction, by enabling parents to advocate for their child, and adjust their lives to the disorder.

With regard to treatment, some parents perceived therapies as difficult to access, a burden financially, difficult to implement, and not all to be effective. Others however stated otherwise, noting positive experiences about the treatment used. This inconsistency in parents' perceptions may indicate differences in children's and parental needs, due to the heterogeneity of autism in terms of symptoms and severity between individuals. ${ }^{2,398}$ It may also be due to poorly structured interventions, leading to inconsistent outcomes in therapy. ${ }^{99}$ The lack of awareness among policy makers may be another possibility affecting accessibility and funding.

These contradictory opinions call for individualization of therapy, where the needs of each child and the family are considered and met. Such needs may be influenced by the nature of the child's disorder and the parents' expectations of the outcomes, which were found to be different among parents in the synthesized results. Nevertheless, to determine these needs requires parents' involvement in the therapy, allowing them to make informed decisions. This was observed to be lacking by some parents as their opinions were dismissed, leaving them with an impression that they were not recognized as experts in the care of their child. Additionally, being involved in the therapy process would help parents gain a sense of control in managing their child.

For example, structuring the therapy process by having implementation guidelines could also help in providing consistent outcomes in therapy. ${ }^{99}$ This includes reducing the high turnover rates of therapists, which is a genuine concern due to the intolerability to changes in an autistic child that can worsen symptoms and affect the outcomes in therapy. Finally, informing policy makers on accessibility and funding restrictions coupled with the importance of individualization would promote efficiency, whereby accessibility and funding are provided according to the needs of individual families. 


\section{Limitations}

Several limitations were identified in relation to the articles included in this meta-synthesis. First, non-English articles were excluded due to the lack of translational services, which could have resulted in the exclusion of significant articles. However, only three such articles were identified while assessing the eligibility of full text articles. ${ }^{100-102}$ This number can be said to be small and may not have affected the results of this meta-synthesis.

The restrictions on the age of children with autism to the childhood period were intended to provide a focused viewpoint on parents' experiences of this age group. However, several $(n=11)$ studies included had child participants who were above the stated age range and could not be selectively excluded, contributing $2 \%$ of the total child participants. Three studies also included interviews of extended family members and had to be selectively extracted with caution.

Other than having a greater number of included articles that described only the mother's perspectives compared to fathers, articles that included both parents also had a greater number of mothers as participants compared to fathers. This is because mothers are generally the primary caregivers of children and hence have more exposure in caring for the child. However, the shortage of perspectives from fathers provides an uneven contribution to the synthesis that is biased toward the perspective of mothers. Caution should thus be practiced when applying these findings as the parents' experiences with the child with autism may have sex differences in how mothers and fathers cope with their child.

Finally, the studies included in this meta-synthesis dated back to the year 1999. The time elapsed would have resulted in changes in diagnostic procedures, social norms, and health care services and practices. This in turn can lead to changes in parents' perspectives, which may not reflect present issues. The findings in this meta-synthesis should therefore be interpreted with care in its implications on current practice, taking into account the advancement in medical science and civilization.

\section{Conclusion}

In conclusion, parents' physical and psychological well-being was observed to be affected, both positively and negatively, while raising a child with autism in the childhood period. This impact on well-being and quality of life is expected to continue as the child progresses into adolescence and adulthood, ${ }^{85,92}$ but it is not the focus of this meta-synthesis and requires further research. Challenges that negatively affected parents' psychological well-being arose from the child's behaviors, the parents' perception of the child, or the label of autism.

Various external sources contributed as well, such as the family, financial constraints, lack of social support, and the shortcomings of health care practices and policies. The results of the synthesis are consistent with the literature, whereby parents in families confronted with autism have increased stress levels or more mental health illnesses compared to families with other disabilities or typical families ${ }^{22,23,84,92}$ and is related to the care of the child in the various ways stated. $83,86,89,94,97,103$

In turn, the benefits of support came in many forms from the family, friends, support groups, and health care professionals, and these were greatly valued by parents. Backed by the literature, the presence of support countered the negative impact of having a child with autism, ${ }^{93,94,104}$ enabling parents to cope with the disorder and change their perception of the child to a more positive and hopeful one. The provision of timely, adequate, and continuous support to parents is therefore important in empowering parents to adapt to the lifetime diagnosis of autism, which can be addressed by improvements in public awareness, policy making, and health care practices. Such improvements should involve recognizing parents as experts of their child, an important aspect observed to be lacking among health care professionals and the public alike. Hearing parents out to identify their individual family needs and not just the affected child should also be encouraged to direct services that are resourceful and necessary to the family.

\section{Acknowledgments}

This systematic review was supported by a research grant from the School of Pharmacy, Monash University Malaysia. No source of funding was received for this study.

\section{Author contributions}

All authors contributed toward data analysis, drafting and critically revising the paper and agree to be accountable for all aspects of the work.

\section{Disclosure}

The authors report no conflicts of interest in this work.

\section{References}

1. Desai MU, Divan G, Wertz FJ, Patel V. The discovery of autism: Indian parents' experiences of caring for their child with an autism spectrum disorder. Transcult Psychiatry. 2012;49(3-4):613-637.

2. McConkey R, Truesdale-Kennedy M, Cassidy A. Mothers' recollections of early features of autism spectrum disorders. Child Adolesc Ment Health. 2009; 14(1):31-36. 
3. National Institution of Mental Health [webpage on the Internet]. Depression. 2011; Available from: http://www.nimh.nih.gov/health/ publications/depression/index.shtml?ct=39994. Accessed January 26, 2015.

4. Medeiros K, Winsler A. Parent-child gesture use during problem solving in autistic spectrum disorder. J Autism Dev Disord. 2014;44(8): 1946-1958.

5. Blumberg SJ, Bramlett MD, Kogan MD, Schieve LA, Jones JR, Lu MC. Changes in Prevalence of Parent-Reported Autism Spectrum Disorder in School-Aged U.S. Children: 2007 to 2011-2012. Atlanta, GA: National Center for Health Statistics; 2013.

6. Charman T, Baird G. Practitioner review: diagnosis of autism spectrum disorder in 2- and 3-year-old children. J Child Psychol Psychiatry. 2002;43(3):289-305.

7. American Psychiatric Association [webpage on the Internet]. DSM-5 Fact Sheet - Autism Spectrum Disorder. 2013; 2. Available from: http:// www.psychiatry.org/practice/dsm/dsm5. Accessed January 25, 2015.

8. Chamak B, Bonniau B, Oudaya L, Ehrenberg A. The autism diagnostic experiences of French parents. Autism. 2011;15(1):83-97.

9. Zeedyk SM, Rodriguez G, Tipton LA, Baker BL, Blacher J. Bullying of youth with autism spectrum disorder, intellectual disability, or typical development: victim and parent perspectives. Res Autism Spectr Disord. 2014;8(9):1173-1183.

10. Farrugia D. Exploring stigma: medical knowledge and the stigmatisation of parents of children diagnosed with autism spectrum disorder. Sociol Health Illn. 2009;31(7):1011-1027.

11. Ludlow A, Skelly C, Rohleder P. Challenges faced by parents of children diagnosed with autism spectrum disorder. J Health Psychol. 2012; 17(5):702-711.

12. Kingston $C$, Hibberd C, Ozsivadjian A. Parent experiences of a specialist intervention service for mental health difficulties in children with autistic spectrum disorder. Child Adolesc Ment Health. 2013;18(2):109-115.

13. Corsello CM. Early intervention in autism. Infants Young Child. 2005;18(2):74-85.

14. Gray DE. Gender and coping: the parents of children with high functioning autism. Soc Sci Med. 2003;56(3):631-642.

15. Dale E, Jahoda A, Knott F. Mothers' attributions following their child's diagnosis of autistic spectrum disorder: exploring links with maternal levels of stress, depression and expectations about their child's future. Autism. 2006;10(5):463-479.

16. Zhou T, Yi C. Parenting styles and parents' perspectives on how their own emotions affect the functioning of children with autism spectrum disorders. Fam Process. 2014;53(1):67-79.

17. Davis NO, Carter AS. Parenting stress in mothers and fathers of toddlers with autism spectrum disorders: associations with child characteristics. J Autism Dev Disord. 2008;38(7):1278-1291.

18. Poslawsky IE, Naber FB, Van Daalen E, Van Engeland E. Parental reaction to early diagnosis of their children's autism spectrum disorder: an exploratory study. Child Psychiatry Hum Dev. 2013;45(3): 294-305.

19. O' Halloran M, Sweeney J, Doody O. Exploring fathers' perceptions of parenting a child with Asperger syndrome. J Intellect Disabil. 2013; 17(3):198-213.

20. Gray DE. Negotiating autism: relations between parents and treatment staff. Soc Sci Med. 1993;36(8):1037-1046.

21. Osborne LA, Reed P. Stress and self-perceived parenting behaviors of parents of children with autistic spectrum conditions. Res Autism Spectr Disord. 2010;4(3):405-414.

22. Estes A, Olson E, Sullivan K, et al. Parenting-related stress and psychological distress in mothers of toddlers with autism spectrum disorders. Brain Dev. 2013;35(2):133-138.

23. Dabrowska A, Pisula E. Parenting stress and coping styles in mothers and fathers of pre-school children with autism and down syndrome. J Intellect Disabil Res. 2010;54(3):266-280.

24. Sharma S, Winter D, McCarthy M. A personal construct approach to understanding stress in mothers of children diagnosed with autism spectrum disorders. J Constr Psychol. 2013;26(1):50-61.
25. Hartley SL, Barker ET, Seltzer MM, Greenberg JS, Floyd FJ. Marital satisfaction and parenting experiences of mothers and fathers of adolescents and adults with autism. Am J Intellect Dev Disabil. 2011; 116(1):81-95.

26. Walsh D, Downe S. Meta-synthesis method for qualitative research: a literature review. J Adv Nurs. 2005;50(2):204-211.

27. Schreiber R, Crooks D, Stern P. Qualitative meta-synthesis; issues and techniques. In: Morse J, editor. Completing a Qualitative Project; Details and Dialogue. Thousand Oaks, CA: Sage; 1997:311-326.

28. DePape AM, Lindsay S. Parents' experiences of caring for a child with autism spectrum disorder. Qual Health Res. 2015;25(4):569-583.

29. Corcoran J, Berry A, Hill S. The lived experience of US parents of children with autism spectrum disorders: a systematic review and meta-synthesis. J Intellect Disabil. 2015;19(4):356-366.

30. Chamak B, Bonniau B. Changes in the diagnosis of autism: how parents and professionals act and react in France. Cult Med Psychiatry. 2013;37(3):405-426.

31. Jacob SA, Khan TM, Ong YS, Ooi KL. A meta-synthesis on parenting a child with autism. PROSPERO 2015:CRD42015015756. Available from: http://www.crd.york.ac.uk/PROSPERO/display_record. asp? ID $=$ CRD42015015756

32. Luong J, Yoder MK, Canham D. Southeast Asian parents raising a child with autism: a qualitative investigation of coping styles. $J$ Sch Nurs. 2009;25(3):222-229.

33. Mitchell C, Holdt N. The search for a timely diagnosis: parents' experiences of their child being diagnosed with an autistic spectrum disorder. J Child Adolesc Ment Health. 2014;26(1):49-62.

34. Zuckerman KE, Sinche B, Mejia A, Cobian M, Becker T, Nicolaidis C. Latino parents' perspectives on barriers to autism diagnosis. Acad Pediatr. 2014;14(3):301-308.

35. Aylaz R, Yilmaz U, Polat S. Effect of difficulties experienced by parents of autistic children on their sexual life: a qualitative study. Sex Disabil. 2012;30(4):395-406.

36. Koydemir-Ozden S, Tosun U. A qualitative approach to understanding Turkish mothers of children with autism: implications for counselling. Aust J Guid Counsell. 2010;20(1):55-68.

37. Alqahtani MM. Understanding autism in Saudi Arabia: a qualitative analysis of the community and cultural context. J Pediatr Neurol. 2012; 10(1):15-22.

38. Abbott M, Bernard P, Forge J. Communicating a diagnosis of autism spectrum disorder - a qualitative study of parents' experiences. Clin Child Psychol Psychiatry. 2013;18(3):370-382.

39. Altiere MJ, von Kluge S. Searching for acceptance: challenges encountered while raising a child with autism. J Intellect Dev Disabil. 2009;34(2):142-152.

40. Mulligan J, MacCulloch R, Good B, Nicholas DB. Transparency, hope, and empowerment: a model for partnering with parents of a child with autism spectrum disorder at diagnosis and beyond. Soc Work Ment Health. 2012;10(4):311-330.

41. Midence K, O'Neill M. The experience of parents in the diagnosis of autism. A pilot study. Autism. 1999;3(3):273-285.

42. Myers BJ, Mackintosh VH, Goin-Kochel RP. "My greatest joy and my greatest heart ache:" Parents' own words on how having a child in the autism spectrum has affected their lives and their families' lives. Res Autism Spectr Disord. 2009;3(3):670-684.

43. Fletcher PC, Markoulakis R, Bryden PJ. The costs of caring for a child with an autism spectrum disorder. Issues Compr Pediatr Nurs. 2012; 35(1):45-69.

44. Ballan MS. Parental perspectives of communication about sexuality in families of children with autism spectrum disorders. $J$ Autism Dev Disord. 2012;42(5):676-684.

45. Dickie VA, Baranek GT, Schultz B, Watson LR, McComish CS. Parent reports of sensory experiences of preschool children with and without autism: a qualitative study. Am J Occup Ther. 2009;63(2):172-181.

46. Marquenie K, Rodger S, Mangohig K, Cronin A. Dinnertime and bedtime routines and rituals in families with a young child with an autism spectrum disorder. Aust Occup Ther J. 2011;58(3):145-154. 
47. Schaaf RC, Toth-Cohen S, Johnson SL, Outten G, Benevides TW. The everyday routines of families of children with autism: examining the impact of sensory processing difficulties on the family. Autism. 2011; 15(3):373-389.

48. Matthews RA, Booth SM, Taylor CF, Martin T. A qualitative examination of the work-family interface: parents of children with autism spectrum disorder. J Vocat Behav. 2011;79(3):625-639.

49. Joosten AV, Safe AP. Management strategies of mothers of school-age children with autism: implications for practice. Aust Occup Ther J. 2014; 61(4):249-258.

50. Hall HR, Graff JC. Parenting challenges in families of children with autism: a pilot study. Issues Compr Pediatr Nurs. 2010;33(4):187-204.

51. Markoulakis R, Fletcher P, Bryden P. Seeing the glass half full: benefits to the lived experiences of female primary caregivers of children with autism. Clin Nurse Spec. 2012;26(1):48-56.

52. McCabe H. Employment experiences, perspectives, and wishes of mothers of children with autism in the People's Republic of China. J Appl Res Intellect Disabil. 2010;23(2):122-131.

53. Zhang W, Yan TT, Barriball KL, While AE, Liu XH. Post-traumatic growth in mothers of children with autism: a phenomenological study. Autism. 2015;19(1):29-37.

54. Marshall V, Long BC. Coping processes as revealed in the stories of mothers of children with autism. Qual Health Res. 2010;20(1):105-116.

55. Woodgate RL, Ateah C, Secco L. Living in a world of our own: the experience of parents who have a child with autism. Qual Health Res. 2008;18(8):1075-1083.

56. Safe A, Joosten A, Molineux M. The experiences of mothers of children with autism: managing multiple roles. J Intellect Dev Disabil. 2012;37(4):294-302.

57. Lin CR, Tsai YF, Chang HL. Coping mechanisms of parents of children recently diagnosed with autism in Taiwan: a qualitative study. J Clin Nurs. 2008;17(20):2733-2740.

58. Meirsschaut M, Roeyers H, Warreyn P. Parenting in families with a child with autism spectrum disorder and a typically developing child: mothers' experiences and cognitions. Res Autism Spectr Disord. 2010; 4(4):661-669.

59. Jegatheesan B, Miller PJ, Fowler SA. Autism from a religious perspective: a study of parental beliefs in South Asian Muslim immigrant families. Focus Autism Other Dev Disabl. 2010;25(2):98-109.

60. Kuhaneck HM, Burroughs T, Wright J, Lemanczyk T, Darragh AR. A qualitative study of coping in mothers of children with an autism spectrum disorder. Phys Occup Ther Pediatr. 2010;30(4):340-350.

61. Valentine K. A consideration of medicalisation: choice, engagement and other responsibilities of parents of children with autism spectrum disorder. Soc Sci Med. 2010;71(5):950-957.

62. Carbone PS, Behl DD, Azor V, Murphy NA. The medical home for children with autism spectrum disorders: parent and pediatrician perspectives. J Autism Dev Disord. 2010;40(3):317-324.

63. Bundy MB, Kunce LJ. Parenting stress and high functioning children with autism. Int J Disabil Hum Dev. 2009;8(4):401-410.

64. Neely-Barnes SL, Hall HR, Roberts RJ, Graff JC. Parenting a child with an autism spectrum disorder: public perceptions and parental conceptualizations. J Fam Soc Work. 2011;14(3):208-225.

65. Green VA. Parental experience with treatments for autism. J Dev Phys Disabil. 2007;19(2):91-101.

66. Papageorgiou V, Kalyva E. Self-reported needs and expectations of parents of children with autism spectrum disorders who participate in support groups. Res Autism Spectr Disord. 2010;4(4):653-660.

67. Grindle CF, Kovshoff H, Hastings RP, Remington B. Parents' experiences of home-based applied behavior analysis programs for young children with autism. J Autism Dev Disord. 2009;39(1):42-56.

68. Braiden H-J, Bothwell J, Duffy J. Parents' experience of the diagnostic process for autistic spectrum disorders. Child Care Pract. 2010; 16(4):377-389.

69. McCabe H. The importance of parent-to-parent support among families of children with autism in the People's Republic of China. Int J Disabil Dev Educ. 2008;55(4):303-314.
70. Tzanakaki P, Grindle C, Hastings RP, Hughes J, Kovshoff H, Remington B. How and why do parents choose early intensive behavioral intervention for their young child with autism. Educ Train Autism Dev Disabil. 2012;47(1):58-71.

71. MacKintosh VH, Goin-Kochel RP, Myers BJ. "What do you like/dislike about the treatments you're currently using?": a qualitative study of parents of children with autism spectrum disorders. Focus Autism Other Dev Disabl. 2012;27(1):51-60.

72. Serpentine EC, Tarnai B, Drager KDR, Finke EH. Decision making of parents of children with autism spectrum disorder concerning augmentative and alternative communication in Hungary. Commun Disord $Q$. 2011;32(4):221-231.

73. Grey I, Lynn E, McClean B. Parents of children with autism: experiences of education service provision in the Republic of Ireland. Ir J Psychol. 2010;31(1-4):111-124.

74. Allgood N. Parents' perceptions of family-based group music therapy for children with autism spectrum disorders. Music Ther Perspect. 2005;23(2):92-99.

75. Nasuno M, Takeuchi K, Yamamoto J-I. Feasibility of parents of children with autism using an applied behavior analytic early treatment program: a preliminary study in Malaysia. Jpn J Spec Educ. 2003; 40(6):723-732.

76. Timberlake MT, Leutz WN, Warfield ME, Chiri G. In the driver's seat: parent perceptions of choice in a participant-directed medicaid waiver program for young children with autism. J Autism Dev Disord. 2014;44(4):903-914.

77. Auert EJ, Trembath D, Arciuli J, Thomas D. Parents' expectations, awareness, and experiences of accessing evidence-based speechlanguage pathology services for their children with autism. Int J Speech Lang Pathol. 2012;14(2):109-118.

78. Benson PR. Coping, distress, and well-being in mothers of children with autism. Res Autism Spectr Disord. 2010;4(2):217-228.

79. Benson PR. Coping and psychological adjustment among mothers of children with ASD: an accelerated longitudinal study. J Autism Dev Disord. 2014;44(8):1793-1807.

80. Pozo P, Sarriá E, Brioso A. Family quality of life and psychological well-being in parents of children with autism spectrum disorders: a double ABCX model. J Intellect Disabil Res. 2014;58(5): $442-458$.

81. Pottie CG, Ingram KM. Daily stress, coping, and well-being in parents of children with autism: a multilevel modeling approach. J Fam Psychol. 2008;22(6):855-864.

82. Beer M, Ward L, Moar K. The relationship between mindful parenting and distress in parents of children with an autism spectrum disorder. Mindfulness. 2013;4(2):102-112.

83. Firth I, Dryer R. The predictors of distress in parents of children with autism spectrum disorder. J Intellect Dev Disabil. 2013;38(2): 163-171.

84. Estes A, Munson J, Dawson G, Koehler E, Zhou XH, Abbott R. Parenting stress and psychological functioning among mothers of preschool children with autism and developmental delay. Autism. 2009; 13(4):375-387.

85. Smith LE, Greenberg JS, Seltzer MM. Social support and well-being at mid-life among mothers of adolescents and adults with autism spectrum disorders. J Autism Dev Disord. 2012;42(9):1818-1826.

86. Hastings RP, Kovshoff H, Ward NJ, degli Espinosa F, Brown T, Remington B. Systems analysis of stress and positive perceptions in mothers and fathers of pre-school children with autism. J Autism Dev Disord. 2005;35(5):635-644.

87. Corman MK. The positives of caregiving: mothers' experiences caregiving for a child with autism. Fam Soc. 2009;90(4):439-445.

88. Hastings RP, Kovshoff H, Brown T, Ward NJ, Espinosa FD, Remington B. Coping strategies in mothers and fathers of preschool and school-age children with autism. Autism. 2005;9(4):377-391.

89. Kayfitz AD, Gragg MN, Orr R. Positive experiences of mothers and fathers of children with autism. J Appl Res Intellect Disabil. 2010; 23(4):337-343. 
90. Baker JK, Smith LE, Greenberg JS, Seltzer MM, Taylor JL. Change in maternal criticism and behavior problems in adolescents and adults with autism across a 7-year period. J Abnorm Psychol. 2011; 120(2):465-475.

91. Smith LE, Greenberg JS, Seltzer MM, Hong J. Symptoms and behavior problems of adolescents and adults with autism: effects of mother-child relationship quality, warmth, and praise. Am J Ment Retard. 2008; 113(5):387-402.

92. Smith LE, Hong J, Seltzer MM, Greenberg JS, Almeida DM, Bishop SL. Daily experiences among mothers of adolescents and adults with autism spectrum disorder. J Autism Dev Disord. 2010; 40(2):167-178.

93. Samadi SA, McConkey R. The impact on Iranian mothers and fathers who have children with an autism spectrum disorder. J Intellect Disabil Res. 2014;58(3):243-254.

94. Hartley SL, Barker ET, Baker JK, Seltzer MM, Greenberg JS. Marital satisfaction and life circumstances of grown children with autism across 7 years. J Fam Psychol. 2012;26(5):688-697.

95. Benson PR, Kersh J. Marital quality and psychological adjustment among mothers of children with ASD: cross-sectional and longitudinal relationships. J Autism Dev Disord. 2011;41(12):1675-1685.

96. Pozo P, Sarria E. A global model of stress in parents of individuals with autism spectrum disorders (ASD). Anal Psicol. 2014;30(1): 181-192.

97. Bishop SL, Richler J, Cain AC, Lord C. Predictors of perceived negative impact in mothers of children with autism spectrum disorder. Am J Ment Retard. 2007;112(6):450-461.
98. Roberts J, Williams K, Carter M, et al. A randomised controlled trial of two early intervention programs for young children with autism: centre-based with parent program and home-based. Res Autism Spectr Disord. 2011;5(4):1553-1566.

99. Stahmer AC, Brookman-Frazee L, Lee E, Searcy K, Reed S. Parent and multidisciplinary provider perspectives on earliest intervention for children at risk for autism spectrum disorders. Infants Young Child. 2011;24(4):344-363.

100. Lee AR, Hong SW, Kim JS, Ju SJ. [Life transition of mothers of children with autism]. J Korean Acad Nurs. 2010;40(6):808-819. Korean.

101. Ben-Cheikh I, Rousseau C. Autisme et soutien social dans des familles d'immigration récente: l'expérience de parents originaires du Maghreb [Autism and social support in recently immigrated families: experience of parents from Maghreb]. Sante Ment Que. 2013;38(1):189-205. French.

102. Senechal C, des Rivieres-Pigeon C. Impact de l'autisme sur la vie des parents [The impact of autism on the life of parents]. Sante Ment Que. 2009;34(1):245-260. French.

103. Kuhlthau K, Payakachat N, Delahaye J, et al. Quality of life for parents of children with autism spectrum disorders. Res Autism Spectr Disord. 2014;8(10):1339-1350.

104. Ekas NV, Lickenbrock DM, Whitman TL. Optimism, social support, and well-being in mothers of children with autism spectrum disorder. J Autism Dev Disord. 2010;40(10):1274-1284.
Neuropsychiatric Disease and Treatment

\section{Publish your work in this journal}

Neuropsychiatric Disease and Treatment is an international, peerreviewed journal of clinical therapeutics and pharmacology focusing on concise rapid reporting of clinical or pre-clinical studies on a range of neuropsychiatric and neurological disorders. This journal is indexed on PubMed Central, the 'PsycINFO' database and CAS,

\section{Dovepress}

and is the official journal of The International Neuropsychiatric Association (INA). The manuscript management system is completely online and includes a very quick and fair peer-review system, which is all easy to use. Visit http://www.dovepress.com/testimonials.php to read real quotes from published authors. 